\title{
Experiências de saúde entre mulheres: reflexões a partir de um programa de rádio comunitária
}

\author{
Women's health experiences: reflections from a community radio program
}

\section{Experiencias de salud entre mujeres: reflexiones a partir de un programa de radio comunitaria}

\author{
Tatiana Rozenfeld ${ }^{1, a}$ \\ tati.rozenfeld@gmail.com | https://orcid.org/o000-0003-1788-9435
}

Wedna Cristina Marinho Galindo $2, b$

wedna.galindo@ufpe.br | https://orcid.org/o000-0001-8839-9375

\footnotetext{
${ }^{1}$ Universidade Federal de Pernambuco, Centro de Ciências da Saúde. Recife, PE, Brasil.

2 Universidade Federal de Pernambuco, Centro de Filosofia e Ciências Humanas, Departamento de Psicologia, Grupo de Estudos Frestas. Recife, PE, Brasil.

a Especialização em Residência Multiprofissional em Saúde da Família pela Universidade Federal de Pernambuco.

boutorado em Psicologia Clínica pela Universidade Católica de Pernambuco.
}

\section{RESUMO}

A pesquisa teve como objetivo identificar aspectos da relação das mulheres consigo mesmas, com o processo de saúde-doença e com o Serviço Integrado de Saúde (SIS), unidade de saúde do Sistema Único de Saúde (SUS) que trabalha com Práticas Integrativas e Complementares em Saúde (PICS). O material de estudo analisou entrevistas do programa 'Mulheres do SIS', veiculadas por uma Rádio Comunitária local. A avaliação do conteúdo do material indica particularidades no modo como as mulheres se apresentam e referem suas experiências no campo da saúde. Usam seu nome e condição laboral para se apresentarem, não utilizando outros marcadores sociais. As PICS são reconhecidas pelas mulheres como práticas significativas de cuidado pela atenção às singularidades e aos coletivos. A fala-escuta das experiências das mulheres, possibilitada pelo programa de rádio, contribui para legitimar suas existências, historicamente silenciadas.

Palavras-chave: Mulheres; Sistema Único de Saúde; Comunicação em Saúde; Processo Saúde-Doença; Integralidade em Saúde.

\section{ABSTRACT}

This research aimed to identify aspects of women's relationship with themselves, with the health-disease process and with the Integrative Healthcare Service (SIS), healthcare unit of the Unified Health System (SUS) that works with Integrative and Complementary Health Practices (PICS). The study was based on women's interviews collected and broadcasted by a local Community Radio during the show called 'Women of SIS'. The content analysis of the material indicates particularities in the way women present themselves 
and talk about their experiences in the health field. They present themselves by name and working condition, not using other social markers to talk about themselves. Women recognize the PICS as important care practices that offer attention to singularities and to the collective. The act of speaking/listening about women's experiences, made possible by the radio show, contributes to legitimize their existences, existences that are historically silenced.

Keywords: Women; Unified Health System (SUS); Health Communication; Health-Disease Process; Integrality in Health.

\section{RESUMEN}

La investigación tuvo como objetivo identificar aspectos de la relación de las mujeres consigo mismas, con el proceso de salud-enfermedad y con el Servicio Integrado de Salud (SIS), unidad de salud del Sistema Único de Salud (SUS) que trabaja con las denominadas Prácticas Integrativas y Complementarias en Salud (PICS). El material del estudio consistió en entrevistas con mujeres que transitaron por lo programa 'Mujeres de SIS', de una Radio Comunitaria local. El análisis de contenido del material muestra las particularidades en la forma en que las mujeres se presentan y refieren sus experiencias en el campo de la salud. Se presentan por nombre y condición laboral; no usan otros marcadores sociales para hablar de sí mismas. Las PICS son reconocidas por las mujeres como prácticas de cuidado significativas debido a la atención a las singularidades y lo colectivo. La escucha del discurso de las vivencias de las mujeres, posibilitada por el programa de radio, contribuye a legitimar sus existencias, históricamente silenciadas.

Palabras clave: Mujeres; Sistema Único de Salud (SUS); Comunicación en Salud; Proceso SaludEnfermedad; Integralidad en Salud.

Contribuição dos autores:

Concepção e desenho do estudo: Tatiana Rozenfeld e Wedna Cristina Marinho Galindo.

Aquisição, análise ou interpretação dos dados: Tatiana Rozenfeld e Wedna Cristina Marinho Galindo.

Redação do manuscrito: Tatiana Rozenfeld e Wedna Cristina Marinho Galindo.

Revisão crítica do conteúdo intelectual: Tatiana Rozenfeld e Wedna Cristina Marinho Galindo.

Declaração de conflito de interesses: não há.

Fontes de financiamento: não houve.

Considerações éticas: não há.

Agradecimentos/Contribuições adicionais: não há.

Histórico do artigo: submetido: 12 dez. 2020 | aceito: 01 mar. 2021 | publicado: 30 jun. 2021.

Apresentação anterior: não há.

Licença CC BY-NC atribuição não comercial. Com essa licença é permitido acessar, baixar (download), copiar, imprimir, compartilhar, reutilizar e distribuir os artigos, desde que para uso não comercial e com a citação da fonte, conferindo os devidos créditos de autoria e menção à Reciis. Nesses casos, nenhuma permissão é necessária por parte dos autores ou dos editores. 


\title{
Vozes-Mulheres \\ (Conceição Evaristo, 2008)
}

A voz de minha bisavó

ecoou criança

nos porões do navio.

ecoou lamentos

de uma infância perdida.

A voz de minha avó

ecoou obediência

aos brancos-donos de tudo.

\begin{abstract}
A voz de minha mãe ecoou baixinho revolta debaixo das trouxas pelo caminho empoeirado rumo à favela

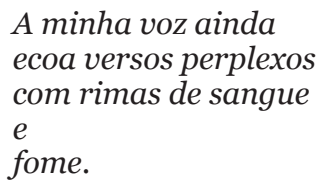
no fundo das cozinhas alheias roupagens sujas dos brancos

A voz de minha filha recolhe todas as nossas vozes recolhe em si as vozes mudas caladas engasgadas nas gargantas.

\author{
A voz de minha filha \\ recolhe em si \\ a fala e o ato. \\ O ontem - o hoje - o agora. \\ Na voz de minha filha \\ se fará ouvir a ressonância \\ O eco da vida-liberdade.
}

\section{APRESENTAÇÃO}

Conceição Evaristo (2008) é uma das grandes referências contemporâneas da literatura afro-brasileira e, enquanto mulher negra e periférica, traz, em suas obras, com sensibilidade aguçada, elementos dessa vivência. Evocar um poema da autora, no início do presente trabalho, não se deve ao acaso. Gerações de mulheres têm tido seus corpos restringidos e suas vozes silenciadas pelas diferentes opressões cotidianas, históricas e estruturais, de uma sociedade essencialmente racista, misógina, machista e classista; simultaneamente, gerações resistem e insistem em ecoar a vida e a liberdade que têm em si - como faz lembrar Conceição Evaristo (2008). Suas vozes entoam memórias e afetos, marcam presença e afirmam existência no modo como compartilham encontros e experiências, assim como as narrativas presentes em 'Mulheres do SIS' - série de entrevistas documentais realizadas com mulheres usuárias do Serviço Integrado de Saúde (SIS), da cidade do Recife, gravadas por uma rádio local, a Rádio Comunitária Aconchego (RCA).

Entende-se que a iniciativa de escutar as mulheres usuárias do serviço público de saúde e difundir suas narrativas é potente, pois possibilita a expressão e a partilha da experiência de um grupo socialmente vulnerabilizado, que tem suas falas e vivências deslegitimadas e abafadas por uma estrutura de sociedade fundamentalmente opressora e patriarcal. Sendo assim, neste trabalho - realizado a partir de atividades vinculadas ao estágio de rede vivenciado, pela primeira autora, no Serviço Integrado de Saúde (SIS), a partir do Programa de Residência Multiprofissional em Saúde da Família da Universidade Federal de Pernambuco 
(UFPE) - desenvolvemos reflexões sobre as práticas integrativas, o SIS e a condição das mulheres em nossa sociedade.

Consideramos cada podcasti publicado na série 'Mulheres do SIS' uma narrativa que compõe histórias reveladas de modo autêntico, tal como Gaskell (2002) argumenta sobre entrevistas narrativas em pesquisa qualitativa. O que o programa da rádio comunitária fez foi facultar às mulheres que utilizassem "sua própria linguagem espontânea na narração dos acontecimentos" (GASKELL, 2002, p. 95).

Foucault (2014) sublinha a noção de que o discurso não é neutro e funciona como parte de um sistema de exclusão em nossa sociedade. $\mathrm{O}$ autor traz à tona um debate que se mantém atual, ao explicitar que pela via do discurso se exercem o poder e a disputa pelo poder, cujo impacto envolve o domínio e a detenção das narrativas e dos discursos sobre objetos do mundo. As provocações formuladas pelo teórico motivaram a realização do presente estudo: "Mas, o que há, enfim, de tão perigoso no fato de as pessoas falarem e de seus discursos proliferarem indefinidamente? Onde, afinal, está o perigo?” (FOUCAULT, 2014, p. 8). As questões do autor contribuíram para pensarmos: o que falam as 'Mulheres do SIS'? O que dizem de si, de suas relações, das realidades em que vivem? Assim, escolhemos o material do podcast como fonte dos discursos das mulheres, cujo 'perigo' é previsível, em contexto de silenciamento que marca a existência delas.

Trabalhamos com o objetivo geral de identificar aspectos da relação das mulheres consigo mesmas, com o processo de saúde-doença e com o SIS. A pesquisa foi orientada pelos seguintes objetivos específicos: i) identificar as práticas terapêuticas referidas pelas mulheres; ii) caracterizar conteúdos de autorreferência das mulheres; iii) caracterizar conteúdos sobre o processo de saúde-doença.

Ainda que o estudo não tenha realizado a etapa denominada construção de dados, pois utilizamos como principal material as narrativas gravadas pela rádio comunitária, ele é caracterizado como estudo qualitativo, cujos fundamentos se situam na pesquisa clínico-qualitativa e na análise de conteúdo. Turato (2000) destaca como elemento central comum às diferentes concepções de pesquisa qualitativa a perspectiva de lançar luz sobre os sentidos e significados de determinados fenômenos em seus contextos. Para tal afirmação, o autor se vale da compreensão de fenômeno desenvolvida e categorizada por Marilena Chaui (1995 apud TURATO, 2000) - que o concebe como um conceito abrangente, referente a tudo que existe e se mostra em certo local, revelando-se de maneiras diversas.

A pesquisa clínico-qualitativa é definida por Turato (2000) como um conjunto de métodos, técnicas e procedimentos que objetiva descrever e interpretar os sentidos e significados atribuídos por indivíduos ou grupos de determinado setting dos cuidados com a saúde, para os fenômenos relacionados às suas próprias vidas. Logo, a partir dos sentidos e modos de vida trazidos pelas narrativas, torna-se possível construir realidades individuais e coletivas, como afirma Gaskell (2002). Conforme conceituado pelo autor, isso ocorre na medida em que uma história é contada encadeando uma sequência de acontecimentos e possíveis explicações para os mesmos, viabilizando a expressão das experiências humanas mais diversas.

Já a análise de conteúdo caracteriza-se como um método que dispõe de variadas técnicas para descrever e organizar elementos presentes no processo de comunicação, possibilitando, a partir de uma sistematização, inferir conhecimentos (CAVALCANTE; CALIXTO; PINHEIRO, 2014). Campos (2004) reforça essa concepção ao afirmar que:

A análise de conteúdo como conjunto de técnicas se vale da comunicação como ponto de partida. Diferente de outras técnicas como a estocagem ou indexação de informações, crítica literária é sempre feita a partir da mensagem e tem por finalidade a produção de inferências. (p. 613).

i Programa de áudio ou vídeo que fica disponibilizado na internet em arquivo de mídia digital. 
Essa produção de inferências se refere à articulação de elementos teóricos e demais dados obtidos no campo, para a compreensão do contexto, possibilitando uma análise crítica do material da pesquisa, conforme conceituam Campos e Turato (2009):

[...] produzir inferências em análise de conteúdo significa, principalmente, produzir conhecimentos subjacentes a determinada mensagem, e também ancorá-las a um quadro de referenciais teóricos, situando-se num paradigma acadêmico, situação concreta que é visualizada segundo o contexto histórico e social de sua produção. (p. 126).

Como ressalta Fischer (2001), o discurso põe em funcionamento enunciados e relações, não havendo uma verdade unívoca por trás do mesmo, mas uma produção histórica. $\mathrm{O}$ autor explica que, através do discurso, acessamos uma perspectiva de análise perpassada pelas intencionalidades e pelos desejos dos próprios agentes e das relações que estabelecem naquele contexto.

Diante do exposto, interessou-nos explorar, a partir dos relatos das 'Mulheres do SIS', quais relações elas estabelecem com o tema pelo qual foram convocadas a dialogar no programa da rádio, a saber, o SIS e sua experiência. Antes de apresentar nossa análise das referidas relações (item 4), indicamos como o artigo está organizado. O item 2 apresenta uma contextualização do SIS e da rádio comunitária. Abordamos a política nacional de Práticas Integrativas e Complementares em Saúde (PICS), bem como a discussão teórica envolvendo mulheres e o processo de saúde-doença. No item 3, descrevemos procedimentos da pesquisa (o material utilizado, tratamento dado a ele e nossos achados). A discussão dos achados compõe o item 4 e é sucedida pelas Considerações finais.

\section{SERVIÇO INTEGRADO DE SAÚDE E A RÁDIO COMUNITÁRIA ACONCHEGO}

No âmbito nacional, Recife (PE) foi uma das cidades precursoras na área das PICS, tendo implementado, no ano de 2004, seu primeiro serviço municipal de referência em práticas integrativas: a Unidade de Cuidados Integrais à Saúde (UCIS) - Professor Guilherme Abath (AROUCHA, 2010). Já a segunda UCIS da cidade se instituiu em 2013 e compõe um dos dispositivos que formam o Serviço Integrado de Saúde $(\text { SIS })^{\mathrm{ii}}$, sendo referida atualmente como UCIS-SIS (RIBEIRO, 2014).

Além de abarcar uma Unidade de Referência em Práticas Integrativas, a UCIS-SIS, o atual SIS funciona como Programa de Extensão da UFPE e como Núcleo Comunitário de Cultura, Comunicação e Saúde. Segundo Arimatéia (2016), o projeto de implantação da UCIS-SIS se deu por meio de uma parceria do Centro de Ciências da Saúde (CCS), da UFPE, com a Secretaria Municipal de Saúde, quando já havia atividades comunitárias sendo realizadas no local. Nesse sentido, por suas particularidades, o autor caracteriza o SIS como um "equipamento social" composto que extrapola tal denominação, por considerá-lo também um "centro social” (ARIMATÉIA, 2016, p. 18).

A UCIS-SIS compõe a rede de atenção básica do Recife e, sendo referência para todo o município, em conjunto com a UCIS Professor Guilherme Abath, recebe usuárias e usuários por encaminhamento de outros serviços da rede, bem como por demanda espontânea. Entre as práticas e atividades desenvolvidas atualmente no SIS, estão: biodança, terapia comunitária, terapia bioenergética, acupuntura, curso de plantas medicinais, ioga, Lian Gong, tai chi chuan, dança do ventre, capoeira, aula de automassagem e de alongamento, pilates de solo, constelação familiar, aula de percussão, grupo de artesanato etc.

Ressaltamos que o serviço conta com um fórum de usuárias, que se organiza de modo autônomo para levantar pautas coletivas, realizar bazar, cinedebates mensais e outras atividades. O SIS também abriga uma rádio comunitária, a Rádio Comunitária Aconchego, que constitui uma iniciativa de comunicação

ii Inicialmente, este equipamento era nomeado Centro Integrado de Saúde (CIS). Atualmente se chama Serviço Integrado de Saúde (SIS) e é composto por três esferas: comunitária, universitária e da saúde. 
comunitária e tem o propósito de democratizar a comunicação, a cultura e a informação com uma programação diversificada de músicas, programas e atividades (RÁDIO ACONCHEGO, 2021b).

\section{Política Nacional de Práticas Integrativas e Complementares (PNPIC)}

A Política Nacional de Práticas Integrativas e Complementares (PNPIC), instituída pela Portaria GM/ MS nº 971, em maio de 2006, determina os objetivos e as diretrizes para a implementação de experiências com práticas integrativas no Sistema Único de Saúde (SUS), no âmbito dos estados e municípios. A política em questão prevê, "na perspectiva da prevenção de agravos e da promoção e recuperação da saúde" (BRASIL, 2006), o fortalecimento do cuidado continuado, humanizado e integral, na atenção básica. Desse modo, visa gerar aumento na resolubilidade do sistema e ampliação do acesso às práticas alternativas e complementares, bem como promover a racionalização das ações de saúde, estimular ações referentes ao controle e à participação social envolvendo usuários, gestores e trabalhadores (BRASIL, 2006).

Entre as práticas previstas na política estão, inicialmente, aquelas associadas a medicina tradicional chinesa, acupuntura, homeopatia, fitoterapia, medicina antroposófica e termalismo-crenoterapia (BRASIL, 2006). Mais tarde, com a aprovação da Portaria GM/MS nº 849 de 2017, diversas práticas foram incluídas, tais como a arteterapia, a ayurveda, a biodança, a dança circular, a meditação, a musicoterapia, a naturopatia, a osteopatia, a quiropraxia, a reflexoterapia, o reiki, a shantala, a Terapia Comunitária Integrativa e a ioga (BRASIL, 2017).

A PNPIC (2006) surge para consolidar o cuidado em saúde pautado na compreensão do sujeito e de seu processo de saúde-doença de maneira complexa e integral, com ênfase na atenção básica, envolvendo práticas em saúde que possuem paradigmas diferentes daquele 'biomédico', centrado na doença. Sendo assim, a política contempla o designado campo de "sistemas médicos complexos e recursos terapêuticos", que contém um modo ampliado e próprio de compreender o processo saúde-doença, diagnóstico e terapêutica (BRASIL, 2006). Tal campo é denominado pela Organização Mundial da Saúde (OMS) parte da Medicina Tradicional e Medicina Complementar e Alternativa (MT/MCA). A primeira se refere à medicina desenvolvida por diversas culturas, e a segunda, àquelas que fazem um contraponto à medicina dominante, de modo geral (ANDRADE; COSTA, 2010).

Segundo Foucault (1999), a perspectiva biomédica está atrelada ao pensamento da medicina moderna positivista, que exerce poder sobre os sujeitos e a sociedade, atuando e produzindo verdades sobre os mesmos. Nesse sentido, o autor explica que, a partir do século XIX, a medicina ocidental hegemônica se configurou como um saber-poder, constituindo, assim, o nomeado sistema de 'biopoder', que age continuamente sobre os corpos através de tecnologias e mecanismos disciplinares e regulamentadores de poder.

A crítica ao modelo hegemônico e dominante do fazer médico e da saúde como um todo é expressa amplamente pelo paradigma do movimento da Reforma Sanitária. De acordo com Escorel (1999), o movimento tem origem nas críticas ao modelo norte-americano preventivista de saúde travadas no contexto acadêmico, no final dos anos 1960 e início da década de 1970. Nesse período, o Brasil sofria uma Ditadura Militar e essas críticas ao positivismo na saúde foram sendo fomentadas, sobretudo, dentro das universidades, nos Departamentos de Medicina Preventiva e Social (DMPS). O movimento ampliou o debate em torno da saúde atrelando-o a outras disputas por direitos sociais, na perspectiva da luta pela democracia (ESCOREL, 1999).

De acordo com Escorel (1999), nesse período se produziu conhecimento relativo ao estado da saúde da população e à perspectiva de intervenção sanitária, gerando consequências nas práticas políticas no campo. Uma das críticas à abordagem da medicina preventivista diz respeito à mitificação do campo social, ao reduzir sua compreensão a relações de causa e efeito e enfatizar, principalmente, as atitudes dos profissionais como perspectiva de mudança, como explica a autora. No entanto, o discurso preventivista 
foi incorporado na América Latina de modo distinto daquele dos Estados Unidos, que se caracterizava por uma perspectiva liberal; mais especificamente, no Brasil, este pensamento estava voltado para o papel do Estado na assistência à saúde, sendo enquadrado a um modelo racionalizador de mudanças nas práticas institucionais.

Escorel (1999) destaca que na mesma época, dentro dos DMPS, se difundiu a medicina comunitária, coerente com o debate internacional marcado pela Declaração de Alma-Ata - que apontava como estratégia para as políticas de saúde o fortalecimento da atenção básica com o mote 'Saúde para todos no ano 2000'. Tal documento provém da Conferência Internacional sobre Cuidados Primários de Saúde de 1978 (Conferência de Alma-Ata) e representa um marco histórico no debate da saúde coletiva - é o momento em que se anunciam as recomendações sobre o fortalecimento das medicinas tradicionais e as práticas complementares.

Em suas reflexões, Escorel (1999) identifica um interesse, na América Latina, pelo desenvolvimento dos programas de medicina comunitária, que tinham um enfoque médico-social e visavam a uma atuação mais ampla e politizada na saúde, com participação comunitária - o que apontava para um debate sobre a desmedicalização da sociedade. Aumentava-se, portanto, a cobertura assistencial ao mesmo tempo que se realizavam pesquisas sobre "modelos alternativos de atenção médica" (ESCOREL, 1999, p. 23), e, assim, a atenção à saúde no Brasil se direcionava gradualmente para a perspectiva do fortalecimento da atenção básica, como sugerido pelas organizações internacionais e por debates e disputas do movimento da Reforma Sanitária.

Sendo assim, no início dos anos 1980, o movimento e as experiências em atenção primária inspiraram a reordenação do setor da saúde, culminando na $8^{\text {a }}$ Conferência Nacional de Saúde (CNS), em 1986. Por fim, solidificou-se no país o movimento pela democratização da saúde e se lançaram os princípios da Reforma Sanitária, que enfatizam a necessidade de se ampliarem o conceito de saúde e as ações institucionais (BRASIL, 2011). A partir de então, a saúde se afirmou como direito universal e dever do Estado, com a redemocratização do país e a promulgação da Constituição Federal de 1988. Com a aprovação da Lei Orgânica da Saúde (Lei no 8.080, de 1990) instituiu-se o SUS (BRASIL, 2006).

Logo, os princípios da Reforma Sanitária representam a base do SUS e norteiam sua concepção. A perspectiva da atenção e cuidado em saúde integral, humanizada, territorializada, com ênfase na atenção básica e com uma rede de apoio composta por níveis de complexidade; a Política Nacional de Atenção Básica (PNAB) de 2011, a Política Nacional de Práticas Integrativas e Complementares (PNPIC), destacada no presente trabalho; bem como diversas outras políticas que sustentam a prática e a assistência no SUS atualmente, são fruto dessa trajetória de construção, luta e resistência por um sistema de saúde público, universal e gratuito.

Telesi Júnior (2016) destaca que a reafirmação da atenção básica, enquanto estratégia para a saúde pública nos anos 1980, contribuiu para uma maior legitimação das práticas integrativas e intensificou os debates em torno das abordagens da MT/MCA nos contextos institucionais. O autor explica que, com a criação do SUS, se consolidou o cenário propício para a implantação de experiências pioneiras na perspectiva das práticas integrativas, impulsionadas pela descentralização e pela participação popular. Portanto, em 2003, após a OMS publicar o documento ‘Estratégia da OMS sobre Medicina Tradicional 2002-2005', inicia-se no Brasil a elaboração da PNPIC, com a instituição no Ministério da Saúde de um grupo de trabalho com esta finalidade (BRASIL, 2006).

Ressalta-se que a PNPIC preconiza a promoção do autocuidado e a potencialização de saberes coletivos através da criação de vínculos e do protagonismo comunitário, atuando na prevenção de agravos e na "promoção, manutenção e recuperação da saúde baseada em modelo de atenção humanizada e centrada na integralidade do indivíduo" (BRASIL, 2006). Assim, a política tem o propósito de contribuir para a 
corresponsabilidade pela saúde, para a promoção da cidadania e para o acesso a serviços diversificados no âmbito público, concebendo o sujeito de modo integral, com sua singularidade e seus processos de adoecimento e saúde.

\section{Atenção integral à saúde e as Práticas Integrativas e Complementares em Saúde}

Universalidade, equidade e integralidade da atenção à saúde são os princípios básicos que norteiam o SUS e, como pontua Teixeira (2011), são considerados seus "princípios finalísticos" (p. 2), ou seja, são tidos como fundamentais e estruturantes. Eles se articulam com os "princípios estratégicos" (p. 2) de descentralização, regionalização, hierarquização e participação social que, por sua vez, apontam para o modo como o sistema se constituirá, suas diretrizes políticas, organizativas e operacionais. A noção de integralidade como princípio finalístico diz respeito a um modelo de atenção à saúde que envolve uma gama de ações para promoção da saúde, prevenção de riscos e agravos, bem como assistência. Assim, é pertinente para a presente pesquisa conceituá-la, de modo que se aprofunde a compreensão sobre as PICS.

Camargo Jr. (2009) concebe a integralidade como uma "imagem-objetivo" (p. 17) x que nos move e aponta para determinada configuração da realidade, considerada desejável por certos atores políticos. $\mathrm{O}$ autor afirma que, assim sendo, ela pode se tornar real em um tempo definido - o que a diferencia de uma utopia. Posto isso, para além de ser um princípio básico do SUS, articulado aos demais, envolve um conjunto de valores e características vinculados a um ideal de sociedade mais justa.

De acordo com Mattos (2009), embora não haja apenas um significado e um sentido para a integralidade, na medida em que ela se configura como uma noção polissêmica - ou seja, representada por possibilidades diversas -, consideramos que, enquanto 'imagem-objetivo', ela tem a característica comum de crítica a certo modelo de realidade e a perspectiva de superá-lo. No caso, o modelo a ser superado é o paradigma biomédico de saúde, que tem a doença e a medicalização como elementos centrais. Marcado por intervenções tecnicistas, tal modelo fragmenta os sujeitos e o modo de compreendê-los, desconsidera a subjetividade e as particularidades, bem como a relação sistêmica entre a saúde e o modo de vida de cada um, seu contexto, suas relações sociais, familiares e políticas.

Lira, Catrib e Nations (2003) reafirmam que, por essa perspectiva, a doença ocupa um lugar central no processo terapêutico. Além disso, o significado de adoecimento é atribuído unicamente pelo médico- que o concebe essencialmente como expressão de desordem, desequilíbrio e alteração anatômica fisiológica -, limitando a compreensão do fenômeno a elementos técnicos e problemas clínicos (LIRA; CATRIB; NATIONS, 2003). Logo, o modelo de atenção e cuidado integral em saúde e as pautas levantadas pelo movimento da Reforma Sanitária e pela democratização da saúde se configuram como perspectivas contrahegemônicas, visam outras percepções e relações no fazer em saúde, pautado pela via da potencialização da vida, pela produção de autonomia e pela coletividade.

As abordagens preconizadas pelas PICS compreendem o sujeito a partir dessa complexidade, envolvendo aspectos físicos, sociais, mentais, emocionais e espirituais em interação contínua, consideram, portanto, os diversos fatores que interferem na saúde e no bem-estar das pessoas, como explicam Andrade e Costa (2010). Os autores reiteram que tais práticas representam um campo de saberes e cuidados múltiplo e sincrético. Elas se utilizam de tecnologias leves como, por exemplo, métodos diagnóstico-terapêuticos de filosofias orientais, práticas de vivência corporal e de autoconhecimento, bem como práticas associadas ao naturalismo e à ecologia. 


\section{Mulheres e o processo de saúde-doença}

As mulheres são os sujeitos que mais buscam os serviços do SIS. Por esse motivo e pelas particularidades de suas demandas, a presente pesquisa tem como enfoque essa população. A condição das mulheres e a saúde delas estão intrinsecamente ligadas às relações de gênero vigentes em nossa sociedade e são marcadas pelos costumes e valores perpetuados historicamente, como ressaltam Carvalho e Dimenstein (2003). Nessa perspectiva relacional, as autoras afirmam que o conceito de gênero contribui para a compreensão dos vínculos e lugares sociais atribuídos culturalmente para homens e mulheres, na medida em que estes são pautados por relações de poder estabelecidas de forma hierárquica.

Silvia Federici (2017) desenvolve uma densa pesquisa histórica feminista traçando a genealogia do poder no contexto de transição do modelo feudal para o capitalismo na Europa. A autora analisa as transformações nas relações patriarcais e a atuação sobre os corpos das mulheres perseguidas pela Inquisição. Representava ameaça para o projeto de poder e para a instauração do capitalismo o encontro de mulheres e a troca de saberes e o domínio sobre seus corpos, suas práticas holísticas ancestrais e o compartilhamento de conhecimentos sobre o uso de plantas medicinais e métodos contraceptivos. Houve, então, o genocídio das mulheres que perpetuavam tais práticas, para que fosse possível levar a cabo o projeto capitalista, na medida em que as mulheres passaram a ser a força de trabalho servil dentro de suas casas, gerando (e gestando) a mão de obra para o sistema e a manutenção da vida doméstica para os trabalhadores assalariados.

O sistema patriarcal no qual estamos inseridas(os) privilegia historicamente a experiência masculina, como reafirma Delajustine (2018). Vale ressaltar que esses sujeitos de privilégios se limitam àqueles que pertencem ao modelo normativo de homem branco cisgênero (cis) ${ }^{i i i}$ heterossexual (AROUCHA, 2010). As opressões do patriarcado afligem, de modo distinto, não apenas as mulheres, mas também sujeitos com outras identidades de gênero e sexualidade, como as pessoas LGBTQIA $+{ }^{\text {iv }}$. Configura-se, portanto, como modelo de dominação que, além de desqualificar, oprimir e explorar de diversas formas, das mais veladas às mais explícitas, tanto as mulheres quanto as pessoas que não se enquadram no modelo de masculinidade tradicional, se articula às demais opressões, como o racismo e o classismo.

Em sua análise, Delajustine (2018) afirma que o modelo de dominação patriarcal limita a autonomia das mulheres, agravando e naturalizando as desigualdades e violências de gênero. A autora explica que esse fenômeno suprime e deslegitima a voz da mulher, enquanto sujeito e ser político: "Esse silêncio forçado não remete à não existência de um discurso feminino, mas sim de discursos masculinos que são reproduzidos e que definem histórica e socialmente a apropriação de corpos - físicos e subjetivos - de mulheres" (DELAJUSTINE, 2018, p. 3).

Para compreender o fenômeno das desigualdades sociais e de suas relações de opressão, confere-se relevância ao conceito teórico-metodológico de interseccionalidade. Como explica Rodrigues (2013), a perspectiva interseccional busca considerar os diversos marcadores sociais, como os de classe, gênero, raça, entre outros, para complexificar a leitura crítica sobre a realidade, seus sistemas de opressão e as relações de poder vigentes. Trata-se de compreendê-los de modo integrado.

De acordo com estudo histórico resgatado por Kyrillos (2020), foi a jurista norte-americana Kimberlé Crenshaw quem criou, em 1989, o conceito de interseccionalidade, como ferramenta analítica para compreender a complexidade dos processos discriminatórios nos diferentes contextos e teorias. A pesquisadora explica que, embora tenha sido cunhado por Crenshaw, a interseccionalidade como perspectiva de debate foi sendo desenvolvida ao longo das décadas anteriores pelos movimentos sociais

iii Termo utilizado para designar indivíduo que possui identidade de gênero consonante com o gênero que lhe foi atribuído ao nascer (GARCIA, [entre 2013 e 2015]).

iv Termo alusivo às pessoas de identidades de gênero e sexualidade não normativas. Refere-se a lésbicas, gays, bissexuais, travestis, transexuais, transgêneros, queers, intersex, agêneros, assexuados e mais (BORTOLETTO, 2019). 
- mais especificamente, pelo movimento feminista negro. Entre diversas outras referências relevantes no campo do debate feminista interseccional, não podemos deixar de mencionar a notória contribuição da intelectual brasileira Lélia Gonzalez, bem como Angela Davis e bell hooks ${ }^{v}$, que apresentam estudos importantes na construção dessa perspectiva de análise teórica.

Considerando o exposto, evidencia-se que o patriarcado está associado ao modelo biomédico de saúde e, portanto, articulado ao biopoder, ao controle e à disciplinarização dos corpos. Dessa forma, diferentes tecnologias e dispositivos de poder atuam de modo a estigmatizar, patologizar e subjugar a população vulnerabilizada. Nessa perspectiva, Carvalho e Dimenstein (2003) alertam, por exemplo, para o consumo abusivo de ansiolíticos por parte das mulheres usuárias da rede de atenção básica à saúde. As pesquisadoras afirmam que a prescrição excessiva de medicamentos, por parte dos profissionais de saúde, reforça uma postura passiva das usuárias diante de seus sofrimentos, desestimulando-as a buscar seus próprios recursos para criar possibilidades para lidar com as angústias e adversidades que vivenciam.

Além das relações de gênero vinculadas a essa realidade, as autoras identificam esse fenômeno como resultado de um tipo de prática e modelo de atenção à saúde, que segue uma lógica assistencialista e responde a uma coerção mercadológica, vinculada à ideologia capitalista de consumo, adaptação ao sistema e à produtividade (CARVALHO; DIMENSTEIN, 2003). Sendo assim, o conceito de determinações sociais em saúde auxilia a compreender o processo de saúde-doença, na medida em que possibilita reconhecer as relações de produção de vida, permeadas pelas contradições inerentes ao sistema capitalista (ROCHA; DAVID, 2015).

Portanto, partimos da perspectiva de que existe uma relação mútua entre o processo de saúde-doença e os aspectos das vivências subjetivas, sociais, políticas e culturais dos sujeitos. Consequentemente, no presente trabalho, consideramos as subjetividades individuais e coletivas para a compreensão das vivências do processo de saúde-doença e do autocuidado das mulheres nas práticas integrativas.

\section{ESTUDANDO MULHERES ACOMPANHADAS PELO SIS}

Neste tópico apresentamos procedimentos envolvidos na pesquisa. Reunimos descrições sobre o material da pesquisa e a estratégia adotada para tratamento dele, bem como apresentamos os conteúdos do podcast, identificados pela análise de conteúdo (CAVALCANTE; CALIXTO; PINHEIRO, 2014).

\section{Material da pesquisa}

A rádio comunitária do SIS, a Rádio Aconchego (2021b), é descrita, em sua página na web, como um espaço que promove trocas e construções coletivas de informações relativas ao território, à saúde, à cultura, ao lazer e à política, na perspectiva de combater as opressões e fortalecer o protagonismo comunitário. O principal material de análise foram as narrativas de mulheres usuárias do SIS, gravadas e publicadas no período de abril a maio de 2018 pela rádio.

Trata-se de cinco entrevistas individuais gravadas no formato de podcast em áudio, que compõem uma série - classificada como 'minidocumentário' - intitulada 'Mulheres do SIS', disponibilizadas na página web da rádio. De acordo com a descrição, o programa teve o intuito de ser mais um recurso terapêutico que provocasse a autorreflexão, além de proporcionar visibilidade para a fala e as vivências dessas mulheres (RÁDIO ACONCHEGO, 2021a).

Compreendendo a pertinência de escutar as experiências e percepções das próprias usuárias para o aprofundamento do tema, e reconhecendo a potência do material produzido de forma autônoma pelos integrantes da rádio comunitária do SIS, a Rádio Aconchego, optou-se por utilizar o material das entrevistas

v A autora opta pelo pseudônimo escrito em letras minúsculas. 
para constituir o corpus de análise desta pesquisa. A observação como residente-psicóloga da primeira autora e a produção de diário de campo compõem estratégias de contato com o campo da pesquisa. Portanto, a pesquisa foi desenvolvida em etapas.

Inicialmente, houve a inserção no local com a produção do diário de campo. Produzido ao longo dos três meses de estágio da residente, este abarca informações coletadas relativas ao contexto do SIS, sua forma de organização e articulação com a rede de atenção à saúde do município, com a comunidade e a universidade. Além disso, contempla registros das percepções da pesquisadora decorrentes de sua integração nas atividades ofertadas e desenvolvidas no SIS e da convivência com os diferentes atores que compõem aquele espaço: trabalhadores, usuários, comunitários e professores.

A partir do material que compõe os podcasts, foram realizadas a transcrição dos áudios das cinco entrevistas e a leitura flutuante do seu conteúdo para, então, desenvolver a categorização do material transcrito em três grupos: (a) conteúdos de autorreferência das mulheres; (b) práticas terapêuticas referidas pelas mulheres; (c) conteúdos sobre o processo de saúde-doença. Por fim, foram realizadas a análise do material sistematizado e a articulação com o referencial teórico e os demais materiais coletados na experiência participativa no campo.

\section{Conteúdo dos podcasts}

Cada episódio do podcast é composto pela fala de uma usuária entrevistada individualmente e editado com pausas ao longo de sua narrativa, sendo excluída a voz (as falas) da entrevistadora. A duração média dos programas, incluindo suas pausas e desconsiderando a música final, é de sete minutos.

O conteúdo de autorreferência trazido nas entrevistas pelas usuárias aparece no início de cada episódio. Elas se apresentam indicando características pessoais como nome e idade, bairro de residência próximos ao SIS e desde quando frequentam o serviço. Além disso, fazem referência à sua vida laboral. É digno de nota que a dimensão do trabalho, seja do trabalho em curso ou da aposentadoria, é usada pelas mulheres para falar de si, a despeito de outros aspectos como raça, classe e gênero.

Sobre a motivação para frequentarem o SIS, as entrevistadas referem curiosidade e busca de ajuda/ acolhimento. Foram convidadas diversas vezes por amigas ou vizinhas antes de decidirem ir até o serviço. Há referências também a convites para participação em práticas específicas, no caso, Lian Gong e dança do ventre. Destacamos o que conta uma das entrevistadas ao ter chegado ao SIS “muito arisca" (e. 1)

Quanto às práticas, as mulheres fazem referência a ioga, automassagem, massoterapia, osteopatia, acupuntura, constelação familiar, dança do ventre, terapia bioenergética, dança circular e biodança, sendo a última a mais mencionada. As mesmas são citadas como práticas, oficinas, aulas, terapias ou vivências. Já os profissionais são referidos pelos seus nomes próprios, por apelidos ou como professores, com a exceção de uma das entrevistas, em que um profissional foi citado como doutor.

Ao falar das práticas, elas observam que há maior participação de mulheres. Dizem que isso se deve a um fator cultural, no qual as mulheres se atêm mais ao cuidado de modo geral. Além disso, ressaltam o caráter coletivo das atividades, frisando o aspecto da comunicação entre as(os) usuárias(os), e trazem elementos da própria história de vida, das conquistas pessoais e do processo de saúde-doença:

As práticas em grupo, elas me ajudaram muito assim, porque como as práticas eram com pessoas, muita gente na sala, então eu tive que aprender a conviver com pessoas, é... aprender a escutar as pessoas, a falar também, a me ouvir. (e. 1).

vi Para manter o sigilo das usuárias, as entrevistas foram enumeradas em ordem distinta daquela dos episódios e foram identificadas pela abreviatura 'e.' seguida do número atribuído à entrevistada. Foram usados nomes fictícios, quando nomes próprios são referidos. 
Eu lembro que eu dancei muita ciranda, quando criança, e o dançar que eu gosto muito então, é tipo assim, uma brincadeira. Ela é um presente pra tudo que eu passei então, é tipo assim: eu vim, tô me curando e a dança circular é tipo uma festa de comemoração por tudo aquilo que eu tô evoluindo e tô absorvendo aqui no SIS. (e. 2).

Ao discorrer sobre a experiência que têm com as práticas e a relação com os processos pessoais, citam as repercussões na vida e o desejo de manter tal atividade. Além disso, falam sobre a compreensão pessoal em relação às práticas, seus objetivos, bem como características do modo como são conduzidas pelos profissionais mediadores:

Porque uma pessoa chegou e fez uma vivência comigo, que eu tinha feito assim que eu cheguei, e eu vi a diferença entre a primeira e a segunda vivência. Então, eu tava mais equilibrada e pude ajudar ela ou passar pra ela uma certa segurança que depois ela me agradeceu e tudo, mas eu acho que não tem que agradecer a ninguém. Ali a gente tá pra acolher, como eu fui acolhida. (e. 2).

Ai tem isso, né?, a comunicação do olhar e do movimento e, na próxima aula, você vai falar como se sentiu com aquilo que você praticou. (e. 4).

Já na ioga a gente trabalha mais a respiração, exercícios corporais mesmo, e trava nas... acho que nas aflições. A gente fica toda travada. Então, a ioga ajuda nisso, a gente relaxar e diminuir as dores do corpo. A bioenergética, ela passa pra mim assim... o que eu consigo colocar pra fora. As minhas frustrações, os meus medos... através dos exercícios que ela manda fazer. (e. 3).

Para falar sobre o SIS como um todo, as entrevistadas utilizam expressões como: "lugar perfeito" (e. 2), "minha segunda casa" (e. 4), "um ventre de mãe" (e. 3), "sem o SIS, eu já não sou mais Maria” (e. 3). Consideram o serviço como um local de "acolhimento"acolhimento", de "cura" e convivência:

É, então, aqui é o lugar de acolhimento que... deveria ser visto com mais carinho pelos nossos governantes, né? [...] O SIS, ele trata da pessoa antes que a pessoa adoeça, tá entendendo? Então aqui é... a gente cura a alma e quando a gente cura a alma a gente não adoece. A gente consegue sentir autoestima, sentir prazer pela vida... e tudo isso não tem como adoecer. (e. 2).

Eu acho que ter convivido com mulheres, né?, que... eu acho que todas as práticas que eu fiz, a maioria foi com mulheres. É... Eu convivi com muitas mulheres sábias aqui, tanto as terapeutas como as mulheres que também faziam parte das práticas. Mulheres muito sábias e trazia muito dessa ancestralidade, essa coisa que nos identifica como pessoa, como mulher. [...] É impressionante como num espaço só a gente consegue ter todas essas, se ligar a todas essas energias assim. A comunicação, a saúde, a autocriação. Isso aqui deveria permanecer para sempre assim na vida das pessoas. (e. 1).

O primeiro Carnaval que eu brinquei foi no SIS, primeiro Carnaval! (e. 3).

Quando se referem a elementos do seu estado emocional, seu bem-estar, seu sofrimento e seu processo de saúde-doença, as entrevistadas fazem um contraponto de como se sentiam anteriormente e como se sentem no momento da entrevista. Sendo assim, quando falam do passado, contam aspectos da sua história de vida, eventos marcantes que lhes causaram sofrimento, vinculados ao seu contexto familiar e social - e 
utilizam-se de expressões como: "fiquei sem chão" (e. 4), "eu era muito angustiada" (e. 5), "desequilibrada" (e. 2), "eu sofri durante oito anos" (e. 2), "eu me sentia só" (e. 2).

Ao falar do momento presente, elas observam mudanças, dizem se sentirem melhor e mais autoconfiantes e identificam aspectos do autoconhecimento e da convivência como catalizadores desse processo:

Hoje eu olho com a minha visão a minha história e vejo a vida... vejo a história de outras pessoas [...] aquele choro que eu não conseguia identificar, hoje em dia eu consigo compreender. (e. 2).

Eu percebo assim que melhorou a minha ansiedade, sabe? Melhorou bastante. Essa autoconfiança de assim, determinação, de resolver as coisas, entende? Essa parte melhorou também. (e. 5).

Eu acho que isso tudo [de ter convivido com "mulheres sábias"] tem ajudado bastante nessa autocura. (e. 1).

Quando falam sobre seu processo de saúde-doença, mencionam o cuidado consigo mesmas e com os outros, dizendo que antes despendiam muita energia para cuidar dos outros e que atualmente cuidam mais de si:

Hoje não [não só cuida dos outros]. Hoje eu dei tarefas e tarefas pra cada pessoa da casa e hoje eu cuido mais de mim. Hoje eu me sinto... vou citar assim... uma borboleta. Eu me sinto uma borboleta... Borboleta voa, borboleta tem liberdade, borboleta é colorida. A gente não vê os dentes da borboleta, mas a gente acha, toda hora, quando a gente olha pra borboleta, que a borboleta tá sorrindo. Então pronto, eu tô sempre sorrindo, sempre abraçando as pessoas, aconselhando, dando o melhor de mim, né? Acolhendo... (e. 4).

\section{MULHERES E SUAS VOZES}

Fazer ressoarem vozes de mulheres contando suas experiências e percepções, a partir do programa da rádio, reflete um posicionamento político necessário quando se propõe alargar a representatividade na produção de informações e na atuação social. As práticas de atribuir relevância às narrativas de mulheres e de dedicar espaço para que sejam compartilhadas combatem a prevalência comumente vista do discurso patriarcal, que, como bem ressalta Delajustine (2018), silencia as mulheres de modo opressivo e violento.

No que se refere à montagem dos episódios do podcast, supõe-se que perguntas diretivas foram feitas às mulheres, e destacamos aqui que a edição da narrativa delas é notável. A decisão sobre o roteiro, bem como os procedimentos a serem adotados na construção do material do programa, é uma escolha da equipe realizadora. Assim, o que indicamos como aspectos analíticos é que o roteiro parece ter seguido um padrão que envolveu: apresentação pessoal da mulher entrevistada; referência à motivação de como chegou ao SIS e o impacto que isso causou na vida dela; quais as práticas de que participa; e como percebe o serviço. Não cabe aqui discutir e/ou sugerir alterações do roteiro do programa. Entretanto, é digno de nota que a estratégia parece dar destaque à importância do SIS na vida das mulheres. Nesse sentido, o programa atende à estratégia de aproximação e fortalecimento do vínculo do SIS junto às usuárias e à população em seu entorno, que tem acesso à rádio.

Dado que o material aqui analisado foi editado pelas(os) realizadoras(es) do programa, a apreciação que é feita do conteúdo considera aquilo expresso pelas mulheres, o contexto de saúde e do SIS. Sendo assim, na apresentação que fazem de si, foi notória a relevância conferida à sua condição laboral e ao seu local de moradia, informações consideradas nesta análise como sendo de autoreferência, indicando que são, possivelmente, elementos identitários relevantes para elas. Entretanto, esses são marcadores 
convencionais, restritos ao nome, endereço e trabalho, não sendo referidos outros indicadores identitários como classe social, raça e etnia e orientação sexual, que apresentariam a interseccionalidade de marcadores sociais que interferem na representatividade dessas mulheres.

Explicitar tais marcadores sociais e identitários tem como finalidade política superar opressões sociais, que marcam violentamente as experiências subjetivas e objetivas dessas mulheres. O conceito de interseccionalidade nos auxilia a compreender as relações de poder e a entender a interferência que os marcadores sociais têm sobre a manutenção de uma estrutura social desigual e opressiva, como explica Rodrigues (2013). Essa realidade, muitas vezes negada tanto socialmente quanto individualmente, está atrelada ao processo de saúde-doença e repercute na promoção do bem-estar e do cuidado de si dos sujeitos em questão. Pontuamos que ações de comunicação, especialmente das mídias independentes, como a rádio comunitária, podem interferir nesse modo de apresentação das pessoas e dar mais visibilidade aos marcadores sociais identitários.

Apesar de reconhecerem que o SIS se constitui por atividades e práticas diversas e abrangentes, que incluem "a comunicação, a saúde, a autocriação" (e. 1), quando as entrevistadas discorrem sobre a atenção à saúde do serviço, sugerem alusão a um modelo de caráter totalizante e biomédico, numa perspectiva assistencialista do serviço e de suas práticas, invertendo a intenção contra-hegemônica das PICS de tornar as(os) usuárias(os) protagonistas de seus processos de cuidado. Nesse sentido, mantém-se a lógica dualista de saúde e doença, bem como um modelo de sujeito passivo no cuidado à saúde - pessoa que é 'tratada' por outrem, personificado como 'O SIS'.

Silva (2019) endossa o argumento de que há, pelas PICS, uma aposta em outras possibilidades de cuidado em saúde pautadas por uma ética da integralidade e pela constante troca com saberes diversos, saberes populares. A autora reitera que o trabalho pelas PICS é um fazer subversivo, contra-hegemônico, de resistência, que exige problematização nos contextos acadêmicos dos modos de se pensar o processo saúde-doença, deslocando olhares para a emergência de novas possibilidades de afetações. Podemos acrescentar que essa mesma exigência - da criação de espaços de problematização e construção coletiva sobre o entendimento do processo de saúde e os jogos de poder e verdade intrínsecos - se mostra necessária no dia a dia dos diversos agentes envolvidos nos serviços de saúde como um todo, tanto usuários como trabalhadores e gestores.

Notamos que, embora as usuárias compreendam a promoção à saúde e demonstrem apropriação sobre a perspectiva da integralidade, há uma reafirmação do modelo biomédico, que socialmente ainda é mais difundido e hegemônico. Vale lembrar que o modelo integral em saúde e o biomédico coexistem, gerando, por vezes, sobreposições e ambiguidades, na medida em que, como exposto anteriormente, a integralidade se configura como uma 'imagem-objetivo' a ser alcançada para superar o paradigma biomédico (MATTOS, 2009).

As falas de exaltação e elogio às qualidades do SIS, algo comum entre as entrevistadas, podem estar associadas tanto a um contentamento genuíno com o serviço quanto a um desejo delas em fortalecê-lo e garantir sua permanência. A satisfação das mulheres com o serviço, bem como suas expectativas e necessidades, não pode ser presumida por suas falas, pois indicadores exigem estudos específicos que distinguem as variáveis que os compõem. Por exemplo, estudos podem ser realizados tanto sobre as percepções e/ou expectativas das mulheres em relação à equipe quanto em relação à estrutura do local, ao tipo de serviço oferecido, entre outras.

Nessa perspectiva, Esperidião e Trad (2006) discorrem sobre a dificuldade teórico-conceitual de se estabelecer referências estáveis e consensuais em estudos relativos à satisfação de usuários e usuárias em serviços de saúde. Entre as questões problematizadas pelas autoras está o emprego da categoria 'expectativa', 
que pode estar impregnada por uma visão idealizada do serviço, além de, nem sempre, nos estudos, vir acompanhada da noção de necessidade, considerada categoria relevante no campo da saúde coletiva.

A ênfase dada pelas entrevistadas aos aspectos positivos do SIS com o intuito de fortalecer o serviço se justificaria, na medida em que SUS, universidades públicas e outros serviços públicos e de direitos sociais vêm sofrendo diversas ameaças e progressivo desmonte pelo atual governo federal brasileiro. Além disso, no período das entrevistas, existia ainda um processo de pactuação institucional em curso sobre as responsabilidades de cada instância que compõe o SIS, gerando eventual clima de incerteza tanto nos profissionais quanto nos usuários - que sugerem negligência, por parte dos “governantes” (e. 2], na manutenção do espaço.

Outro aspecto que merece destaque é a relação que as entrevistadas estabelecem com o SIS. Elas sugerem vínculo de pertencimento, na medida em que se referem ao serviço como um ambiente acolhedor, que lhes proporciona bem-estar e diminuição do sofrimento associados às trocas e aos processos de autoconhecimento, causados pelas vivências nesse espaço. O sentimento de pertencimento pode ser analisado como elemento catalizador da participação social das usuárias, no que diz respeito às iniciativas coletivas no espaço - por exemplo, atividades organizadas pelo fórum de usuárias - e também como elemento que fortalece os vínculos interpessoais estabelecidos no serviço.

A ênfase dada pelas usuárias às práticas grupais sugere importantes vínculos estabelecidos com profissionais e demais usuárias(os), laços significativos para o processo terapêutico. Referências sobre o que se passa com elas mesmas, na direção de transformar situações e garantir bem-estar, saúde, sugerem processos pessoais significativos. Torna-se evidente que processos tradicionalmente atribuídos à psicoterapia individual são trabalhados no coletivo, pois, como relatam as entrevistadas, memórias despertadas por certas atividades atuam na elaboração e transformação de vivências cotidianas e geram bem-estar no grupo. Sendo assim, as reflexões pessoais, provocadas por vivências e encontros, afirmam o papel da escuta e da convivência no processo de promoção à saúde dessas mulheres, que, a partir de práticas grupais, acessam e elaboram elementos de suas subjetividades.

A valorização das práticas grupais como favoráveis aos processos de saúde também foi identificada por Ferreira Neto e Kind (2010), em pesquisa realizada com usuários, técnicos e gerentes sobre práticas de grupo desenvolvidas por Equipes de Saúde da Família no município de Belo Horizonte. Os resultados confirmam que a criação de espaços grupais se revela uma estratégia de suporte para condições de vida precarizadas pelas desigualdades sociais, permitindo a promoção de sociabilidade e o estabelecimento de laços de amizade e solidariedade. Além disso, os pesquisadores identificam, como efeito desses espaços, a troca de conhecimentos entre profissionais e usuários e o fortalecimento do vínculo entre eles.

A convivência e os laços sociais construídos entre as mulheres se consolidam como elementos importantes para a promoção do autocuidado. Para além do incentivo e da influência de amigas e vizinhas na busca do serviço, esses vínculos estabelecidos agora com 'outras' mulheres do SIS, tanto terapeutas quanto usuárias, conferem a importância das relações de trocas. Merecem destaque o reconhecimento e a valorização dos saberes e das potencialidades que essas mulheres têm - o que remete a um elemento fundamental da educação popular em saúde e da noção de integralidade.

Ao falarem sobre cuidado, as usuárias trazem tanto a perspectiva do cuidado com o outro - e que, no geral, toma forma de afazeres domésticos - como também a do autocuidado/cuidado compartilhado evidenciado nos episódios do podcast, quando elas comentam, por exemplo, se sentirem libertas a partir do momento em que compartilharam tarefas de casa e passaram, assim, a cuidarem mais de si. Nesse sentido, as usuárias identificam o SIS como um potente espaço de cuidado, compartilhamento e convivência para a promoção de saúde, onde há trocas de saberes e interdisciplinaridade. A emblemática afirmativa sobre 
"o primeiro Carnaval" (e. 3) sugere que atividades de convivência e autocuidado passaram a ser realizadas a partir do contato com o SIS.

Aqui, podemos compreender o cuidado, para as mulheres, de duas formas: pela perspectiva do trabalho não reconhecido, que sobrecarrega e oprime as mulheres, privando-as de convivências e responsabilizandoas por todos os afazeres da casa, da família e das relações; e pela via do cuidado coletivo e do autocuidado, que emerge como resistência ao modelo hegemônico de sociedade capitalista patriarcal e de suas forças de poder sobre os corpos. Nesse aspecto, encontra-se o potencial inventivo do cuidado compartilhado entre as mulheres.

O cuidado, portanto, revela-se como uma potência de resistência à lógica capitalista das relações, articulado com a criação de espaços de convivência e troca. Assim como explica Federici (2017), o encontro de mulheres compartilhando vivências e saberes ameaça a estrutura hegemônica capitalista patriarcal. Embora as entrevistadas não explicitem esse aspecto de contravenção social, nós o consideramos potente nessa direção, inclusive pelos relatos de satisfação e bem-estar gerados por esses encontros e pela mudança no posicionamento delas nas relações familiares, por exemplo.

\section{CONSIDERAÇÕES FINAIS}

Ao analisar narrativas de mulheres que participaram do programa 'Mulheres do SIS', veiculado pela Rádio Comunitária Aconchego, foi possível identificar aspectos da relação delas consigo mesmas, com o processo de saúde-doença e com o próprio SIS. Conferimos que a produção e a transmissão do podcast têm relevância de caráter clínico, estético e político. A fala/escuta das experiências e vivências dessas mulheres tem função de testemunhar, reverberar e reafirmar suas histórias de vida, inscrevendo-as no campo coletivo e legitimando suas existências. As PICS atuam para o fortalecimento do fazer em saúde no SUS pela perspectiva da potencialização dos sujeitos, das diversidades e do coletivo.

Embora reproduzam falas que remetem ao modelo biomédico, a ênfase dada pelas entrevistadas às práticas coletivas e ao acolhimento mútuo revela o impacto que a vivência no serviço gerou no modo como percebem a realidade e como lidam com seus processos de saúde-doença, que se mostrou coerente com o paradigma da integralidade e das PICS. Nesse sentido, aponta-se para a necessidade de ampliar o escopo de possibilidades terapêuticas que trabalham com a subjetividade. Deve haver investimento em atividades que vão além da psicoterapia tradicional.

É digno de nota que a presença de valores da cultura biomédica na atenção à saúde é compreensível, considerando que estes ainda compõem o paradigma hegemônico nessa área. Sugerimos investimento em pesquisas que acompanhem esse processo de transição e/ou aprofundem a análise dos aspectos que constituem tal realidade. Críticas à cultura biomédica, no campo da saúde, indicam que ela está associada ao controle dos corpos (FOUCAULT, 1999), a intervenções diretivas com ênfase na doença (CARVALHO; DIMENSTEIN, 2003). Pesquisas que investiguem o assunto poderão indicar caminhos para alterar os valores da cultura biomédica junto às mulheres usuárias dos serviços de saúde. Poderão, inclusive, contribuir para o fortalecimento da perspectiva nomeada, em sua origem, medicina comunitária (ESCOREL, 1999), cuja valorização/reconhecimento por parte das 'Mulheres do SIS' foi identificada nas análises.

O estudo realizado tem a limitação de não envolver pesquisa empírica de coleta de dados, situação que restringe o debate ao material disponível no podcast. Futuras pesquisas em torno da temática podem ser realizadas com a inclusão da construção de dados. Pontuamos, contudo, que é importante garantir espaço para livre expressão das mulheres, protagonistas das relações consigo mesmas, com outras pessoas da sua comunidade, com profissionais de saúde, com instituições - enfim, com a sociedade como um todo. 
Reciis - Revista Eletrônica de Comunicação, Informação \& Inovação em Saúde, Rio de Janeiro, v. 15, n. 2, p. 427-445, abr./jun. 2021 [www.reciis.icict.fiocruz.br] e-ISSN 1981-6278

\section{REFERÊNCIAS}

ANDRADE, João Tadeu de Andrade; COSTA, Liduina Farias da. Medicina complementar no SUS: práticas integrativas sob a luz da antropologia médica. Saúde e Sociedade, São Paulo, v. 19, n. 3, p. 497-508, jul.-set. 2010. DOI: http://dx.doi.org/10.1590/S0104-12902010000300003. Disponível em: https://www.scielo.br/scielo. php?script=sci arttext\&pid=S0104-12902010000300003\&lng=pt\&tlng=pt. Acesso em: 7 maio 2020.

ARIMATÉIA, Ênio de Lima. O Centro Integrado de Saúde (CIS) em Recife: experiência de práticas integrativas. 2016. 252 f. Dissertação (Mestrado em Sociologia) - Centro de Filosofia e Ciências Humanas, Universidade Federal de Pernambuco, Recife, 2016. Disponível em: https://repositorio.ufpe. br/bitstream/123456789/31354/1/DISSERTA \%C3\%87\%C3\%830\%20\%C3\%8Anio\%20de\%20Lima $\% 20$ Arimat\%C3\%A9ia.pdf. Acesso em: 13 mar. 2020.

AROUCHA, Edylla Barbosa Lins. Práticas Integrativas e Complementares: o interesse em formação dos profissionais da estratégia de Saúde da Família. 2010. 55 f. Trabalho de Conclusão de Curso (Residência Multiprofissional em Saúde Coletiva) - Departamento de Saúde Coletiva, Centro de Pesquisas Aggeu Magalhães, Fundação Oswaldo Cruz, Recife, 2010. Disponível em: https://www.arca.fiocruz.br/bitstream/ icict/29882/1/51.pdf. Acesso em: 7 maio 2020.

BORTOLETTO, Guilherme Engelman. LGBTQIA+: identidade e alteridade na comunidade. 2019. 32 f. Monografia (Especialização em Gestão de Produção Cultural) - Centro de Estudos Latino-americanos sobre Cultura e Comunicação, Escola de Comunicações e Artes, Universidade de São Paulo, São Paulo, 2019. Disponível em: https://paineira.usp.br/celacc/sites/default/files/media/tcc/guilherme engelman bortoletto.pdf. Acesso em: 22 fev. 2021.

BRASIL. Conselho Nacional de Secretários de Saúde. Sistema Único de Saúde. Brasília, DF: CONASS, 2011. E-book. (Coleção Para Entender a Gestão do SUS 2011, 1). Disponível em: https://www.conass.org.br/ bibliotecav3/pdfs/colecao2011/livro_1.pdf. Acesso em: 6 maio 2020.

BRASIL. Ministério da Saúde. Gabinete do Ministro. Portaria n 971, de 03 de maio de 2006. Aprova a Política Nacional de Práticas Integrativas e Complementares (PNPIC) no Sistema Único de Saúde. Diário Oficial da União, Brasília, DF, 3 maio 2006. Disponível em: http://bvsms.saude.gov.br/bvs/saudelegis/gm/2006/ prt0971 0305 2006.html. Acesso em: 6 de maio 2020.

BRASIL. Ministério da Saúde. Gabinete do Ministro. Portaria n 849, de 27 de março de 2017. Inclui a Arteterapia, Ayurveda, Biodança, Dança Circular, Meditação, Musicoterapia, Naturopatia, Osteopatia, Quiropraxia, Reflexoterapia, Reiki, Shantala, Terapia Comunitária Integrativa e Yoga à Política Nacional de Práticas Integrativas e Complementares. Diário Oficial da União, Brasília, DF, 27 mar. 2017. Disponível em: http://bvsms.saude.gov.br/bvs/saudelegis/gm/2017/prt0849_28_03 2017.html. Acesso em: 6 maio 2020.

CAMARGO JR., Kenneth Rochel de. Apresentação: as muitas vozes da integralidade. In: PINHEIRO, Roseni; MATTOS, Ruben Araujo de. (org.) Os sentidos da integralidade na atenção e no cuidado à saúde. 8 . ed. Rio de Janeiro: IMS/Uerj: Abrasco, 2009. p. 15-19. E-book. Disponível em: https://lappis.org.br/site/wpcontent/uploads/2017/12/Os-Sentidos-da-Integralidade-na-Aten \%C3\%A7\%C3\%A3o-e-no-Cuidado-\%C3\%A0Sa\%C3\%BAde.pdf. Acesso em: 20 mar. 2020.

CAMPOS, Claudinei José Gomes. Método de análise de conteúdo: ferramenta para a análise de dados qualitativos no campo da saúde. Revista Brasileira de Enfermagem, Brasília, DF, v. 57, n. 5, p. 611-614, set./out. 2004. DOI: https://doi.org/10.1590/S0034-71672004000500019. Disponível em https://www.scielo.br/ scielo.php?script=sci_arttext\&pid=S0034-71672004000500019\&Ing=pt\&tlng=pt. Acesso em: 7 maio 2020.

CAMPOS, Claudinei José Gomes; TURATO, Egberto Ribeiro. Análise de conteúdo em pesquisas que utilizam metodologia clínico-qualitativa: aplicação e perspectivas. Revista Latino-Americana de Enfermagem, Ribeirão Preto, v. 17, n. 2, p. 259-264, mar.-abr. 2009. DOI: http://dx.doi.org/10.1590/ S0104-11692009000200019. Disponível em: https://www.scielo.br/scielo.php?script=sci_arttext\&pid=S010411692009000200019\&Ing=en\&tlng=en. Acesso em: 7 maio 2020.

CARVALHO, Lúcia de Fátima; DIMENSTEIN, Magda. A mulher, seu médico e o psicotrópico: redes de interfaces e a produção de subjetividade nos serviços de saúde. Interações, São Paulo, v. 8, n. 15, p. 37-64, jun. 2003. Disponível em: http://pepsic.bvsalud.org/scielo.php?script= sci arttext \& pid=S1413-29072003000100003 \& Ing=pt $\backslash$ nrm=iso. Acesso em: 20 de mar. de 2020. 
Reciis - Revista Eletrônica de Comunicação, Informação \& Inovação em Saúde, Rio de Janeiro, v. 15, n. 2, p. 427-445, abr./jun. 2021 [www.reciis.icict.fiocruz.br] e-ISSN 1981-6278

CAVALCANTE, Ricardo Bezerra; CALIXTO, Pedro; PINHEIRO, Marta Macedo Kerr. Análise de conteúdo: considerações gerais, relações com a pergunta de pesquisa, possibilidades e limitações do método.

Informação \& Sociedade, João Pessoa, v. 24, n. 1, p. 13-18, 2014. Disponível em: https://periodicos.ufpb.br/ index.php/ies/article/view/10000. Acesso em: 7 maio 2020.

DELAJUSTINE, Ana Claudia. O feminismo como enfrentamento do biopoder em uma sociedade patriarcal. In: CONGRESSO NACIONAL DE BIOPOLÍTICA E DIREITOS HUMANOS, 1., 23-27 abr. 2018, ljuí. Anais [...]. ljuí: Unijui, 2018. Disponível em: https://publicacoeseventos.unijui.edu.br/index.php/conabipodihu/article/ view/9328/7998. Acesso em: 7 de maio 2020.

ESCOREL, Sarah. Reviravolta na saúde: origem e articulação do movimento sanitário. Rio de Janeiro: Editora Fiocruz, 1999. E-book. Disponível em: https://static.scielo.org/scielobooks/qxhc3/pdf/ escorel-9788575413616.pdf. Acesso em: 4 maio 2020.

ESPERIDIÃO, Monique Azevedo; TRAD, Leny Alves Bomfim. Avaliação de satisfação de usuários: considerações teórico conceituais. Cadernos de Saúde Pública, Rio de Janeiro, v. 22, n. 6, p. 1267-1276, jun., 2006. DOI: https://doi.org/10.1590/S0102-311X2006000600016. Disponível em: https://www.scielo.br/scielo. php?script=sci_arttext\&pid=S0102-311X2006000600016\&lng=en\&nrm=iso\&tlng=pt. Acesso em: 10 out. 2020.

\section{EVARISTO, Conceição. Vozes-mulheres. In: EVARISTO, Conceição. Poemas da recordação e outros movimentos. Belo Horizonte: Nandyala, 2008. p.10-11.}

FEDERICI, Silvia. O mundo precisa de uma sacudida. In: FEDERICI, Silvia. Calibã e a bruxa: mulheres, corpo e acumulação primitiva. São Paulo: Editora Elefante, 2017. p. 44-103. E-book. Disponível em: http:// coletivosycorax.org/wp-content/uploads/2016/08/CALIBA E A BRUXA WEB.pdf. Acesso em: 20 mar. 2020.

FERREIRA NETO, João Leite; KIND, Luciana. Práticas grupais como dispositivo na promoção da saúde. Physis: Revista de Saúde Coletiva, Rio de Janeiro, v. 20, n. 4, p. 1119-1142, 2010. Disponível em: https:// www.scielosp.org/article/physis/2010.v20n4/1119-1142/pt/. Acesso em: 20 out. 2020.

FISCHER, Rosa Maria Bueno. Foucault e a análise do discurso em educação. Cadernos de Pesquisa, São Paulo, n. 114, p. 147-223, nov. 2001. DOI: https://doi.org/10.1590/S0100-15742001000300009. Disponível em: https://www.scielo.br/scielo.php?script=sci arttext\&pid=S0100-15742001000300009\&lng=en\&nrm=iso\&tlng=pt. Acesso em: 7 maio 2020.

FOUCAULT, Michel. A ordem do discurso: aula inaugural no Collège de France, pronunciada em 2 de dezembro de 1970. São Paulo: Edições Loyola, 2014.

FOUCAULT, Michel. Aula de 17 de março de 1976. In: FOUCAULT, Michel. Em defesa da sociedade: curso no Collège de France (1975-1976). Tradução de Maria Ermantina Galvão. São Paulo: Martins Fontes, 1999, p. 285-315.

GARCIA, Dantielli Assumpção. Cisgênero. In: UNIVERSIDADE ESTADUAL DE CAMPINAS. Núcleo de Desenvolvimento da Criatividade. Laboratório de Estudos Urbano. Endici: enciclopédia discursiva da cidade. [Campinas: Unicamp, entre 2013 e 2015]. Disponível em: https://www.labeurb.unicamp.br/endici/index. php?r=verbete\%2Fview\&id=80. Acesso em: 22 fev. 2021

GASKELL, George. Entrevistas individuais e grupais. In: BAUER, Martin W.; GASKELL, George. (org.). Pesquisa qualitativa com texto, imagem e som: um manual prático. Rio de Janeiro: Vozes, 2002. p. 64-113.

KYRILLOS, Gabriela M. Uma análise crítica sobre os antecedentes da interseccionalidade. Revista Estudos Feministas. Florianópolis, v. 28, n. 1, e56509, 9 mar. 2020. DOI: http://dx.doi.org/10.1590/18069584-2020v28n156509. Disponível em: https://www.scielo.br/scielo.php?script=sci arttext\&pid=S0104026X2020000100204\&tlng=pt. Acesso em: 24 out. 2020.

LIRA, Geison Vasconcelos; CATRIB, Ana Maria Fontenelle; NATIONS, Marilyn K. A narrativa na pesquisa social em saúde: perspectiva e método. Revista Brasileira em Promoção da Saúde, Fortaleza, v. 16, n. 2, p. 59-66, 2003. Disponível em: https://www.redalyc.org/pdf/408/40816211.pdf. Acesso em: 20 mar. 2020.

MATTOS, Ruben Araujo de. Os sentidos da integralidade: algumas reflexões acerca de valores que merecem ser defendidos. In: PINHEIRO, Roseni; MATTOS, Ruben Araujo de. (org.) Os sentidos da integralidade na atenção e no cuidado à saúde. 8. ed. Rio de Janeiro: IMS/Uerj: Abrasco, 2009. p. 43-68. E-book. Disponível em: https://lappis.org.br/site/wp-content/uploads/2017/12/Os-Sentidos-da-Integralidade-naAten\%C3\%A7\%C3\%A3o-e-no-Cuidado-\%C3\%A0-Sa\%C3\%BAde.pdf. Acesso em: 20 mar. 2020. 
RÁDIO ACONCHEGO. Mulheres do SIS. Recife: Rádio Comunitária Aconchego, [c2021a]. Disponível em: https://radioaconchego.milharal.org/category/programas/mulheres-do-sis/. Acesso em: 6 maio 2020.

RÁDIO ACONCHEGO. Rádio aconchego: quem somos?. Recife: Rádio Comunitária Aconchego, [c2021b]. Disponível em: https://radioaconchego.milharal.org/quem-somos/. Acesso em: 18 fev. 2021.

RIBEIRO, Tiago. CIS - Centro Integrado de Saúde. In: REDE HUMANIZA SUS. [S. I.], 20 maio 2014. Disponível em: http://redehumanizasus.net/84336-cis-centro-integrado-de-saude/. Acesso em: 6 maio 2020.

ROCHA, Patrícia Rodrigues da; DAVID, Helena Maria Scherlowski Leal. Determinação ou determinantes? Uma discussão com base na Teoria da Produção Social da Saúde. Revista da Escola de Enfermagem da USP, São Paulo, v. 49, n. 1, p. 129-135, 2015. DOI: https://doi.org/10.1590/S0080-623420150000100017. Disponível em: https://www.scielo.br/scielo.php?script=sci_arttext\&pid=S0080-62342015000100129\&lng=pt\&nr m=iso\&tlng=pt. Acesso em: 7 maio 2020.

RODRIGUES, Cristiano. Atualidade do conceito de interseccionalidade para a pesquisa e prática feminista no Brasil. In: SEMINÁRIO INTERNACIONAL FAZENDO GÊNERO,10., 16-20 set. 2013, Florianópolis. Anais eletrônicos [...]. Florianópolis: UFSC, 2013. Disponível em: https://poligen.polignu.org/sites/poligen.polignu. org/files/feminismo\%20negro2.pdf. Acesso em: 7 maio 2020.

SILVA, Priscilla Maria de Castro. Prefácio. In: FERREIRA, Berenice (org.). Práticas Integrativas e Complementares nos Serviços Públicos de Saúde: um sonho, uma ideia, uma realidade. Curitiba: Appris, 2019. p. 6-8. E-book.

TEIXEIRA, Carmen. Os princípios do Sistema Único de Saúde. Salvador, 2011. Texto de apoio elaborado para subsidiar o debate nas Conferências Municipal e Estadual de Saúde. Disponível em: https://www.almg. gov.br/export/sites/default/acompanhe/eventos/hotsites/2016/encontro_internacional_saude/documentos/ textos_referencia/07_principios_sistema_unico_saude.pdf. Acesso em: 6 maio 2020.

TELESI JÚNIOR, Emílio. Práticas integrativas e complementares em saúde, uma nova eficácia para o SUS. Estudos avançados, São Paulo, v. 30, n. 86, p. 99-112, jan.-abr. 2016. DOI: https://doi.org/10.1590/ S0103-40142016.00100007. Disponível em: https://www.scielo.br/scielo.php?script=sci_arttext\&pid=S010340142016000100099\&Ing=pt\&tlng=pt. Acesso em: 7 maio 2020.

TURATO, Egberto Ribeiro. Introdução à metodologia da pesquisa clínico-qualitativa: definição e principais características. Revista Portuguesa de Psicossomática, Lisboa, v. 2, n. 1, p. 93-108, jan.-jun. 2000. Disponível em: https://www.redalyc.org/pdf/287/28720111.pdf. Acesso em: 6 maio 2020. 